\title{
Interrogating the Relevance of Home and Community- Based Services in Addressing Old Age Challenges in Lagos State, Nigeria \\ DOI: 10.36108/NJSA/4102/12(0111)
}

\author{
Bola Amaike \\ Department of Sociology \\ Faculty of Social Sciences \\ University of Lagos, Nigeria \\ bolaamaike@yahoo.com, gamaike@unilag.edu.ng
}

\begin{abstract}
The article examines the relevance of informal care in addressing old age challenges in Lagos State. Although informal care is an integral aspect of caregiving in Nigeria, it has received little or no attention because of dearth of policy thrust and framework. Older people in Nigeria receive informal care which helps to promote optimal ageing and socio-economic well-being. A total of 1,321 retired older men and women in Lagos State, who were care recipients, were asked to assess the nature and sources of old age care as well as their preferences for old age care. The findings indicate that older people preferred informal care to institutional care because the former promotes autonomy, independence and respect from caregivers. This article is based on older people's subjective assessment of home and community-based services which serves as a useful guide to researchers and social gerontologists in addressing old age challenges in Lagos State, Nigeria.
\end{abstract}

Keywords: ageing, caregiving, elderly, informal care, home and communitybased services

\section{Background}

Historically, Africans are expected to take good care of their older members within the extended family system. This 'normative' sense of filial piety appears to be fast disappearing because of myriad of social forces such as modernization, industrialization and globalization which have greatly eroded the social fabrics of intergenerational relations and caregiving (Egwu, 2013; Novak, 2012; Xu and Chow, 2011; Amaike, 2009). Nevertheless, home and community-based care is critical to successful ageing. The concept of 'community' care ensures that ageing individuals receive care and support within their familiar contexts. This was possible in the past because members of the extended family lived within a geographical area which promoted care giving especially in times of need. With rapid social change, both familial networks and the community are challenged in their capacities to deliver hitherto traditional support services to the elderly (UNFPA and Help Age, 2012; Aboderin, 2005; Akeredolu-Ale and Aribiah, 2001).

Similarly, most traditional social support systems are deficient in proximity, resilient to change and lack psychological strength and financial resources required to ensure adequate care in old age. Hence, there is need to 
promote grassroots community groups which will emphasize volunteerism and community participation among older people.

Home and community-based care appears to be the most viable strategy to address old age challenges in Nigeria because it will promote the socioeconomic wellbeing of older people without distancing them from their families and close relatives. A critical examination of informal care in Nigeria is imperative because the wellbeing of older people in Sub-Saharan Africa has not received considerable attention despite the challenges that the elderly face in everyday life (Apt, 2002; Aboderin, 2005; UNFPA and HelpAge, 2012). With little or no social protections, most of the aged are unable to meet their basic needs. Therefore, with the estimated growth of older people (60 years and above) in Africa from 42.6 million to 155.4 million people in 2050 (UNPD, 2009), it is imperative to discuss the socio-economic contexts within which this category of people live and will live in the future. Understanding the quality of care and support available to older people is critical to making recommendations for improvement. Similarly, with the changing demographic profile and ageing of most populations in Africa, there are concerns about the overwhelming need for informal care needed to boost the socio-economic wellbeing of older people. Since caregiving is central to traditional old age care systems, there is need to examine the nature and challenges of ensuring sustainability of the informal old age care services in modern society.

Caregiving can be formal or informal depending on the needs of older people and the availability of caregivers. Specifically, informal care covers the extent to which assistance or services provided at homes or within communities meet elders' needs and forestall institutionalization (institutional care or public old age support), which is alien to African culture and contrary to older people's care preference (Donlan, 2011; Amaike, 2009; Aboderin, 2005; Healy, 2002). Care for the aged can range from exceptionally low quality of care (neglectful and abusive care) to exceptionally high care (exemplary and good quality care). In other words, informal care can be adequate or sufficient when most or all older care recipients' needs are consistently and reliably met by care givers in their homes and communities. This is the ideal eldercare which can best be achieved when caregiving and care givers are sensitive to the values and preferences of older people.

Reciprocity and respect are other critical predictors of socio-economic wellbeing in old age (Xu and Chow, 2011; Wu et al., 2005). Specifically, if older people perceive lack of mutuality (reciprocity) or respect in their relationships with caregivers, they are more likely to be depressed and unsatisfied with whatever care is provided. Hence, insensitivity of caregivers can lead to life dissatisfaction and low quality of life in old age. This underscores the need for informal caregivers to be sensitive to the needs and preferences of older persons in order to ensure that services provided achieve their set objectives, namely, to improve the socio-economic well-being and life satisfaction of older people. Since respect and sensitivity to older people are more critical to their well-being than the amount of care provided (Wolff \& 
Agree, 2004), the importance of robust and efficient home and communitybased care in addressing old age challenges and assisting older people to age in place cannot be overemphasized.

Home and community-based service (HBCS) for older people is an integral part of old age care and support. Older people in Nigeria often indicate their preferences for community-based care which should be respected in ensuring that services and assistance provided are sensitive to their peculiar needs and expectations. Informal care is important because it promotes independence of older persons and provides opportunity for them to rely on familiar caregivers. This also ensures that social relationships are built in a way that promotes confidence and intergenerational reciprocity. Generally, older people using community-based care report better indicators of living standards than their counterparts in institutional placement thus underscoring the importance of informal care for older people (Amaike and Bammeke, 2013; Moody, 2012; UNFPA and Help Age, 2012). Since older people prefer to stay at home and 'age in place', home and community-based services provide a viable platform for ensuring social integration of older people in their families and communities. Home and community-based service is consumer-driven which ensures that health status and wellbeing of Nigerian elderly are promoted. The use of loved ones such as family members in providing care for the elderly provides abundant opportunity for the elderly to negotiate old age care which ultimately gives them the autonomy to be active stakeholders in their own care and support. Home and community-based care is also critical in early intervention which prevents older people from requiring long-term care and support or institutional placement on the long run.

Similarly, HCBS promotes social worth and esteem among elderly who feel they are active members (stakeholders) in their own communities. This greatly improves the elders' sense of belonging and social integration so that they can remain socially active and contribute to the development of their families and communities. In developed climes, HCBS promotes the use of intensive case management which helps older people to maintain independence while living in their communities as long as possible. The relevance of HCBS is also anchored on the fact that it strengthens supportive services such as inhome care, meals deliveries and subsides transportation for appointments as well as medication administration and monitoring among others. These various services greatly improve health status and quality of life of older people. Lastly, the use of informal care to carry out activities of daily living (ADLs) and instrumental activities of daily living (IADLs) also helps older people to remain in community (age in place) while contributing their own quota to families and communities. 


\section{Statement of the Problem}

Most elderly people in Nigeria receive informal care at home, often provided by spouses, adult children and other family members or friends (Amaike and Bammeke, 2013; Ejechi, 2013; Aboderin, 2005; Akeredolu-Ale and Aribiah, 2001). Informal care or community-based care is an invaluable source of old age care and support for Nigerian elderly because it provides assistance with activities of daily living without which many elderly will be forced to live in public institutions, often despised by the society and the elderly alike. Therefore, informal care is a veritable alternative source of elder care since it enables older people to remain at home, avoid the costly geriatric care services in institutions as well as delay institutional placement where such facility exists (Amaike \& Bammeke, 2013; Amaike, 2009). The questions raised in this paper include: what is the quality of home and community-based care available to older people in Nigeria? Are home and community-based services relevant to the needs and wellbeing of older people in Nigeria? Do older people get to determine the nature and quality of informal care? What are the instrumentalities/ agencies of state or public support mechanisms available to older people in Nigeria? These are some of the pertinent issues addressed in this article.

The paper seeks to examines the gender differentials in regularity of old age supports from children and relations in Lagos State; determine if there are gender differentials in who should be responsible for old age care and support in Lagos State, ascertain if there are gender differentials in awareness of social welfare services for older people in Lagos State, and discuss the benefits of home and community-based service.

\section{Review of Literature}

Home and community-based care, in the real sense of the term, is not a new phenomenon in Nigeria. Traditionally, families care and support their elderly members in most Nigerian cultures and in some parts of the world. For instance, the Chinese culture for caring for older people is rooted in Confucianism which emphasizes parental devotion (filial piety) while the care of older people is generally accepted as a normative family duty ( $\mathrm{Xu}$ and Chow, 2011; Wu, et al., 2005). Among the Chinese and African people, the care of older people is traditionally the sole responsibility of families, usually adult children. Elder care is often provided at home by spouses, children, inlaws (often daughters-in-law) and other extended family members. In China, families and government turn to nursing homes and other institutional care only as a last resort (Wu, et al., 2005). Similarly, family responsibility for elders is a cultural and legal norm, and it is written into various Chinese laws and policies including the People Republic of China (PRC) Elderly Rights and Protection Laws (1996). 


\section{Gender and Old Age Care}

In Nigeria, institutional care for older people is rarely embraced which has dire consequences for the health and wellbeing of older people who may need such special intervention. Home and community-based service is often provided by informal care givers usually family members (Amaike, 2009; Aboderin, 2005; Apt, 2002). Primarily, the family serves as a buffer against life vicissitudes, threats and losses that older people suffer in the course of growing older. Nevertheless, individual family members differ in their abilities and willingness to provide old age care because of differences in socio-economic characteristics, gender, interpersonal skills and interpretation of intergenerational roles. There are also similarities and differences in the ways women and men receive care in old age usually based on sex roles and gender biases and discrimination. Women are generally perceived as 'helpful' throughout the life course and in most cases, they tend to receive greater informal care in old age (Amaike \& Bammeke, 2013; Egwu, 2013; Novak, 2012; Oppong, 2006; Moody, 2012; Akeredolu-Ale \& Aribiah, 2001). But in Nigeria, experiences indicate that women constitute the highest numbers among the poorest of the poor. This is despite the fact that women are more likely to provide instrumental care and perform caregiving roles even in old age (grandmothers provide child care support). This underscores the roles of traditional gender socialization in caregiving.

In essence, there are gender differences in the quality and quantum of informal old age care in Lagos State. These gender differentials are predicated on the ideology of separate spheres for men and women which make men and women in society to perform different roles and gain access to different types and forms of care in old age. In most societies, women and men are socialized to pursue different lines of roles (activities), that is, women are socialized to nurture while men are groomed to achieve. Women are also seen as care givers while men are seen as breadwinners (Amaike \& Bammeke, 2013; Egwu, 2013; Amaike, 2009). Although the conflicts associated with these gender roles are beginning to wane in high-income countries, there are still huge gaps between the two genders in Nigeria. Older women are more likely than older men to receive and give informal care. Likewise, females (wives, daughters and sisters) are more likely than males (husbands, sons and brothers) to give care and support to older people in Nigeria (Amaike, 2009; Aboderin, 2005; Apt, 2002).

Female family members are also more likely to be forced to meet demanding care giving roles which often alter their work schedules and disrupt their work trajectory (Amaike, 2009). Thus, with the onset of assistance with activities of daily living (ADLs) needs, women assume increasing responsibility for elder care. Activities of daily living (ADLs) involves assistance with performing personal care like bathing and toileting while IADLs involves care giving activities such as transportation and shopping. 


\section{Dimensions of Informal Old Age Care}

Informal care refers to various forms of help and assistance including physical, financial, emotional and spiritual supports that older people receive from people they know, love and are familiar with in their 'own' environments. Culturally, wives and daughters continue to provide the greatest care in old age (Ejechi, 2013; Rosenberg, Jullamate and Azeredo, 2009; Amaike, 2009; Aboderin, 2005) although there are still differences in role obligations discharged toward elderly persons. For instance, despite modernization and social change, Thai society has managed to retain some aspects of its culture that are humane and elder friendly. One of these cultural practices is the obligation to respect and care for older people. Older people are valued, respected and honoured by younger generations and family members which improve the quality of life of Thai elders (Jullamate, 2008; Lehning, Kim and Dunkle, 2013). Thai elder care is entirely informal with more than $90 \%$ of her elderly living with their adult children and relying on their families for support in old age. Older Thais who do not reside with their children are also expected to be visited at least once in a month by their children. This is a good example of effective and efficient familial elder care using home and community-based care system which is largely informal in nature. Nigeria can take a cue from elder care services in Thailand which include financial support, assistance with basic and instrumental activities of daily living as well as psychosocial and spiritual care (Jullamate, 2008).

In Nigeria, adult children continue to be the foundation of old age care and support even though there is clear evidence that this normative sense of filial piety is on a steady decline in many African societies. But, there is still strong preference for home and community-based care which clearly indicates that informal care is a clear response to the yearnings and aspirations of older people in Nigeria (Egwu, 2013; Amaike, 2009; Akeredolu-Ale \& Aribiah, 2001; Apt, 2002). Home and community-based service is often preferred because older people are presumably surrounded by loving family members, friends and loved ones who know and care for them. Community-based care is viewed as less costly than institutional care because it allows family members to provide care and thus bridge the gaps in interpreting older people's values, preferences and personal history which helps to manage their 'cases' more effectively.

The importance of community-based care is enormous. In general, community care means any care given to older persons in the comfort of their homes and familiar environments (communities). It can be in-home care or services in group such as adult day centres or congregate facilities (Amaike \& Bammeke, 2013). Community-based care can be medical or non-medical care aimed at improving the quality of life of older people by assisting them with ADLs or IADLs so that they can age gracefully and in dignity. It can be provided statutorily by government or paid for by groups or individuals (private). Community-based care includes but not limited to recreational activities, volunteering, house maintenance, psychosocial support, companion- 
ship, visitation, physiotherapy, geriatric case management, medication, keeping medical appointments, monitoring of vital signs such as blood pressure (BP) and sugar level among others. Essentially, community care helps to prevent institutional care or hospital care so it is an important alternative strategy to active older persons who wish to remain in their homes or communities while receiving assistance with basic daily needs (Bohman, Van-Wyk and Ekman, 2011, Wister, et al., 2010). Informal care provides opportunity for older people to maintain their independence, since they can go out and come in as they like with families and friends allowed to visit them as often as they desire (Suhonen, Charalambos, Scolt, Katajisto and Puro, 2012; Bronstein, et al., 2011; Swan, et al., 2008; Chapman, Keating and Eates, 2003).

Besides the positive functions of home and community-based care, there are also challenges associated with using family or informal care as proxies for old age care because they may not be professionals who know the current needs and preferences of older people. Care givers may not adopt evidencebased case management nor be privy to latest trends in elder care. No doubt, families and friends may have the history of older people without being conversant with their current and prevailing circumstances and the best strategies that can be used to address the challenges. Families may also be worn out (stressed out or burnt out) from years of continuous and intensive care giving which may make older people susceptible to abuse and neglect rather than 'loving' care and support of their loved ones (Rosenberg, et al., 2009; Wolff \& Agree, 2004; Chapman, 2003). Thus, concern about the quality, feasibility and sustainability of informal care is one of the greatest concerns of social gerontologists and caregivers. The twin factors of feasibility and sustainability are critical to maintaining the socio-economic well-being of older people.

Despite these concerns, Nigerian older people are more likely to use home and community-based services (HCBC) than institutional care, hence, the need to strengthen informal old age care in Lagos State. In a study on black and white American senior citizens' use of care facilities (Lehning et al., 2013; Bohman et al., 2011; Suhonen et al., 2012), older people consistently show preferences for home and community-based care rather than institutional placements. Most elderly wish to remain in their own homes or communities and avoid institutional placement such as Nursing homes or old people's homes (Egwu, 2013; Akeredolu-Ale \& Aribiah, 2001).

\section{Theoretical Underpinnings}

In our quest to understand and explain the relevance of informal care in promoting the socio-economic well-being of older people, the author adopts two theoretical orientations namely modernization theory of ageing and activity theory of ageing. 


\section{Modernization theory of Ageing}

The ageing of the Nigerian population has implications for the roles and status of older people as well as their support in old age. Historically, the status of older people was low in hunting and gathering societies but was improved in stable agricultural societies where land ownership was vested in the family heads usually older people. But with the advent of industrialization, modernization and globalization, the social roles and status of older members in modern societies dwindled culminating in consistent and continuous depreciation of elders' relevance and socio-economic well-being.

Clearly, Nigeria's transition has eroded the social relevance of older people thus creating an erroneous impression about older people as social burden and societal 'drag'. This partly explains the frailty of filial piety which hitherto sustained older people in Nigeria (Amaike, 2009; Cowgill, 1974). Some aspects of modernization theory have been confirmed in some societies where elders experienced a drastic drop in their roles, status and relevance as the society modernized (Atchley, 1985; Cowgill, 1974; Cowgill and Holmes, 1972). In most cases, traditional old age supports through the extended family is grossly inadequate in addressing old age challenges in Nigeria because of myriad of social changes which have drastically altered the tenets and norms of intergenerational relations and transfers.

These social forces have redefined the care and support available to older people hence underscoring the need for more innovative and sustainable care model for older people in Nigeria. Therefore, home and community-based care is best suited to address old age challenges so that elder care can be modified as the Nigerian society modernizes or transits from an agrarian society to a quasi-capitalist or modernizing society. In most urban centers like Lagos State, older people are seldom integrated into the society because of the negative assessment of their roles and relevance. However, this is not the experience of all older people in all societies. There are societies like the Thai and Chinese societies where older people are adequately supported to live healthily and gracefully. This is because population ageing and its corresponding care demands are crucial global concerns because of the quest of modern societies to ensure that as people age; they can have access to adequate old age care and support (Novak, 2012; Amaike, 2009; Moody, 2002; Bengtson et al., 1997). There is also need for concerted efforts which will ensure that both formal and informal systems are integrated to promote graceful ageing among older Nigerians. It is against this background that younger generations are challenged to assume more responsibilities in the discharge of filial obligations aimed at improving the well-being of older people in Nigeria.

It is hoped that home and community-based services will revitalize the norms of filial piety in modern societies where ageing individuals will be respected and empowered to remain socially active and relevant. This is akin to pre-industrial African societies where elders' needs were accepted and met as the collective responsibilities of the extended families and the communities at large. Modernization theory has been criticized for failing to demonstrate 
convincingly the aspects of pre-industrial societies considered to be the 'golden age' of ageing which are lost as a result of modernization. The theory has also been accused of over-simplification of concepts such as modernization and status of older people which are equally dynamic in nature. Social welfare services and social protection systems in most high income countries have greatly improved the living conditions of older people, hence reducing the incidence of old age poverty. Evidence abounds to indicate that societies can actually modernize and still integrate older people as we have in many industrializing societies such as China and Nigeria. For instance, older people in Africa and Asia still enjoy relatively high degree of respect and relevance in their communities.

\section{Activity theory of Ageing}

Activity theory is one of the earliest sociological theories that attempts to explain factors responsible for successful adaptation and ageing in later life. Burgess (1960) viewed old age as a "role less" role hence the need to remain active in later life. He challenged individuals to replace lost roles with new ones in order to adapt to various role transitions (Novak, 2012; Amaike, 2009; Matcha, 1997; Bengtson, 1997). The theory proposes that active older people, especially those who are supported to remain active in families and communities are more likely to have access to adequate informal care and be satisfied with later life than their counterparts without such supports. In essence, the theory links continued engagement of older people with higher social integration, better social contacts and enhanced socio-economic wellbeing in old age.

Studies have also shown that active older people or those successful at maintaining social contacts in their communities have access to more social supports and invariably they are more satisfied in retirement than those who are fully 'disengaged' from the society as residents in care institutions (Lemon, Bengtson and Peterson, 1972). This indicates that older people who receive care and support in familiar terrains such as personal homes and communitybased facilities are more likely to be actively integrated in society and report better living conditions in old age. Research findings have confirmed some aspects of activity theory (Novak, 2012; Moody, 2012; Matcha, 1997). From literature, older people's engagement in socio-economic activities, social integration and continued relevance in community positively enhance their health status and life satisfaction in most societies (Novak, 2012; Atchley, 1985; Lemon et al., 1972). On the other hand, Szinovacz (1996) observed that informal activities (community-based services and volunteerism), older people's attitude and expectations about what constitutes social engagements are more important determinants of subjective assessment of well-being in old age rather than mere engagement in activities for the sake of activities in old age. 


\section{Methods}

This study was a cross-sectional survey of 1,321 retired older men and women in Lagos State covered through the use of questionnaire and twenty in-depth interviews among executive members of Nigeria Union of Pensioners. The respondents were older pensioners from the three tiers of government in Nigeria (Federal, State and Local Government areas) and the organized private sector. The study adopted a systematic sampling method which sampled representative proportions (at least 10\%) of two institutions each in the public sector. The lists of retirees in these selected institutions were randomly selected for inclusion in the study. With the aid of a stratified multi-stage sample design,1,321 formal sector retirees were successfully covered in the survey. At the first stage, the formal sector was divided into two main groups: public and organized private sector. Secondly, the public sector was further divided into three levels: Federal, State and local government areas. Thirdly, the 1,321 retirees were stratified on the basis of socio-economic and demographic characteristics before selecting the sample. Fourthly, the specific units of analysis were selected from the list of pensioners (through pension schedules) with the aid of systematic random sampling method starting from a randomly selected point $\left(5^{\text {th }}\right.$ position) on the pension schedule until the last element was chosen for inclusion in the survey. In-depth interviews were conducted for purposely selected twenty executive members of Nigeria Union of Pensioners and pension managers in the State.

\section{Data analysis}

The paper adopted both univariate and bivariate analyses to examine formal sector retirees' assessment of home and community-based service in Lagos State, Nigeria. The statistical significance level for Chi-square analysis was set at less than 0.05. Analyses were done using Statistical Package for Social Sciences (SPSS). Content analysis was used to analyze qualitative data.

\section{Major Findings and Discussions}

THE socio-demographic characteristics of the respondents are displayed in Table 1. The majority of the elderly were Lagos State retirees $(56.6 \%)$, followed closely by Federal Government retirees (31.7\%). More than half of them $(64.2 \%)$ were males compared to $(35.8 \%)$ who were females. Most respondents (62.8) were at least 65 years old while $86.5 \%$ was married. About one-third of them $(31.1 \%)$ had five children; the proportion of respondents most whose children were gainfully employed was $30.8 \%$, while only $14.8 \%$ had all children gainfully employed. The employment status of adult children is considered important as a predictor of likelihood to discharge filial piety (informal care) because it has implication for the quality and types of support available to older people at homes and in communities. The elderly with children who were gainfully employed had access to more financial and material supports than those whose children were not gainfully employed. About half of the study population (50.5\%) received supports from spouses, 
adult children and other relations in old age. This underscores the importance of informal social support systems in ensuring that older people have adequate care and support. Slightly one-third of respondents (38.9\%) assessed the quality of informal support received as just okay and fair, this means that only 'minimal' needs were met which justifies the need for a robust, integrated, holistic and comprehensive framework for elder care in Nigeria. The collaborative efforts of both state and non-state actors will go a long way in addressing most old age challenges in Nigeria. In this study, Nigerian elderly claimed that informal social support system assisted them through financial assistance, in-kind and instrumental supports among others.

Table1: Percentage Distribution of Respondents by Socio-Demographic Characteristics

\begin{tabular}{|c|c|c|c|}
\hline Characteristics & Male $N=848$ & Female $N=473$ & Total $N=1321$ \\
\hline \multicolumn{4}{|l|}{ Age groups } \\
\hline Less than 55 years & 0.2 & 0.0 & 0.2 \\
\hline 55- 59 years & 12.7 & 18.4 & 14.8 \\
\hline $60-64$ years & 18.8 & 24.3 & 20.7 \\
\hline $65-69$ years & 27.1 & 27.3 & 27.2 \\
\hline $70-74$ years & 33.4 & 23.7 & 29.9 \\
\hline $75-79$ years & 5.2 & 4.2 & 4.8 \\
\hline 80 years and above & 0.9 & 1.5 & 1.1 \\
\hline \multicolumn{4}{|l|}{ Types of marriage } \\
\hline Monogamy & 85.7 & 90.3 & 87.2 \\
\hline Polygamy & 11.5 & 5.8 & 9.6 \\
\hline No response & 2.8 & 3.9 & 3.1 \\
\hline \multicolumn{4}{|l|}{ Educational attainment } \\
\hline No formal education & 9.8 & 10.8 & 10.1 \\
\hline Primary Education & 23.3 & 23.9 & 23.5 \\
\hline Secondary Education & 31.8 & 28.8 & 30.7 \\
\hline NCE/OND Degree & 12.4 & 16.9 & 14.0 \\
\hline First Degree & 14.7 & 13.3 & 14.2 \\
\hline Masters Degree & 4.0 & 4.2 & 4.1 \\
\hline Doctoral Degree & 1.3 & 0.4 & 1.0 \\
\hline Can’t say & 1.4 & 0.4 & 1.1 \\
\hline \multicolumn{4}{|c|}{ Nature of last employment } \\
\hline Managerial & 25.9 & 22.6 & 24.8 \\
\hline Teaching & 8.1 & 14.6 & 10.4 \\
\hline Bureaucratic & 65.9 & 62.8 & 64.8 \\
\hline Total & 100.0 & 100.0 & 100.0 \\
\hline
\end{tabular}

\section{Gender and Informal Old Age Care}

In terms of gender differences, majority of the respondents, $712(53.9 \%)$ had between five and six children. A slightly higher proportion of female retirees 
(57.3\%) compared to male retirees $(52.0 \%)$ was in this category. A significant number of retirees, $136(10.3 \%)$ had no surviving child, with a higher proportion among male retirees, (13.7\%) compared to female retirees $(4.2 \%)$. This is instructive because of the general belief that adult children will care and support older people in Africa (intergenerational wealth transfer). Studies have also established that childless older people are more likely to be neglected and vulnerable to suffer multiple deprivations (Amaike, 2009; Apt, 2002; Akeredolu-Ale and Aribiah, 2001; Togonu-Bisckersth, 1997). This study also assessed the occupancy status of older people which is considered a factor in determining access to informal care and life satisfaction. Specifically, a higher proportion of male respondents, 255 (30.1\%) owned their houses compared to female respondents, $129(27.3 \%)$. This means that men are more likely to own their houses and lived in their own houses than women in retirement. Even when women owned houses, they may not live in such houses because of caregiving demands and preferences to live with their adult children especially after the demise of their husbands. Despite the strong belief in the importance of the extended family as a source of support in old age, only few retirees, lived with relations, $10(0.8 \%)$. There was also negligible gender disparity with slightly same proportions of male retirees, $5(0.6 \%)$ and female retirees, $5(1.0 \%)$ living with their relations in retirement.

Most retirees frowned at the idea of living in Old people's Home which is generally believed to be a 'destitute home'. When some respondents were asked if they would like to live in Old people's Home, majority vehemently opposed the idea and one respondent opined that, "God forbid, I am not homeless and I am not barren. Why should I live like a stranger in my own country?" This partly explains the negative attitude of most Nigerians to institutional placement (institutionalization) despite the fact that some older people are sometimes abused by informal care givers at homes. Only six respondents $(0.5 \%)$ lived in Old people's Home, with a higher proportion of male retirees, $5(0.6 \%)$ compared to female retirees, $1(0.2 \%)$ found in this category (Amaike, 2009). Only one-fifth of older people assessed the regularity of supports received from adult children and relations as adequate in meeting their basic needs. This underscores the need for comprehensive public supports to complement familial old age supports in Nigeria (Apt, 2002; Akeredolu-Ale and Aribiah, 2001; Heslop, 1999; Togonu-Bickerseth, 1997). The introduction of non-contributory or universal old age pension will greatly reduce the incidence and prevalence of old age poverty and destitution among Nigerian elderly. There were also gender differences in older people's assessment of the regularity of support from their children and relations in Lagos State, Nigeria. 
Table 2: Sex of respondents and regularity of supports from children and relations

\begin{tabular}{|l|l|l|l|l|l|l|}
\hline Sex & Very regular & Not regular & $\begin{array}{l}\text { Irregular but } \\
\text { ok }\end{array}$ & $\begin{array}{l}\text { Not regular } \\
\text { at all }\end{array}$ & $\begin{array}{l}\text { Not } \\
\text { applicable }\end{array}$ & Total \\
\hline Male & $105(12.4 \%)$ & $160(18.9 \%)$ & $319(37.6 \%)$ & $129(15.2 \%)$ & $135(15.9 \%)$ & $848(100 \%)$ \\
\hline Female & $83(17.5 \%)$ & $72(15.2 \%)$ & $195(41.2 \%)$ & $81(17.1 \%)$ & $42(8.9 \%)$ & $473(100 \%)$ \\
\hline Total & $188(14.2 \%)$ & $232(17.6 \%)$ & $514(38.9 \%)$ & $210(15.9 \%)$ & $177(13.4 \%)$ & $1321(100)$ \\
\hline
\end{tabular}

$\mathrm{X}^{2}-20.938, \mathrm{df}=4, \mathrm{P}<0.001 * * * \quad$ Statistically significant

Most respondents (59.4\%) assessed the regularity of support from children and relations to be grossly inadequate in meeting their basic needs in old age. There were more women $(73.5 \%)$ in this category than men $(61.7 \%)$. Apart from informal social supports, respondents were asked to assess their need for assistance with activities of daily living (ADLs), majority of respondents $(90.8 \%)$ claimed to be active and performed these activities with little or no assistance from care givers which underscores their preferences for in-home and community-based services. Majority of respondents (66.3\%) vehemently opposed the need for assistance with ADLs thus buttressing the fact that older people in Lagos State actually lived independently with minimal assistance required with housekeeping and laundry. Respondents also indicated the persons (agents) they believed should be responsible for old age care and support in Nigeria.

Table 3: Sex of respondents and who should be responsible for old age care and support in Nigeria

\begin{tabular}{|l|l|l|l|l|l|l|l|}
\hline \multicolumn{1}{|c|}{ Sex } & Family & Government & Employers & \multicolumn{1}{c|}{ Elderly } & $\begin{array}{c}\text { Others } \\
\text { (NGOs) }\end{array}$ & Not sure & \multicolumn{1}{c|}{ Total } \\
\hline Male & $226(26.7 \%)$ & $576(67.9 \%)$ & $33(3.9 \%)$ & $0(0.0 \%)$ & $2(0.2 \%)$ & $11(1.3 \%)$ & $848(100 \%)$ \\
\hline Female & $151(31.9 \%)$ & $309(65.3 \%)$ & $4(0.8 \%)$ & $2(0.4 \%)$ & $2(0.4 \%)$ & $5(1.1 \%)$ & $473(100 \%)$ \\
\hline Total & $377(28.5 \%)$ & $885(67.0 \%)$ & $37(2.8 \%)$ & $2(0.2 \%)$ & $4(0.3 \%)$ & $16(1.2 \%)$ & $1321(100 \%)$ \\
\hline
\end{tabular}

$\mathrm{X}^{2}-17.402, \mathrm{df}=5, \mathrm{P}<0.005 * * * \quad$ Statistically significant

Clearly, two-thirds of Nigerian elderly (67\%) expected the government to play a leading role in providing old age care and support. More male retirees expected support from government $(67.9 \%)$ and employers $(3.9 \%)$ than women (65.3\% and $0.8 \%$ respectively). On the other hand, more women $(31.9 \%)$ than men $(26.7 \%)$ believed that family members should be responsible for old age care and support. This is because, culturally, men are expected to be 'breadwinners' and 'heads of households' rather than passive recipients of support. Whereas, in terms of family support, females (wives, daughters and sisters) were identified as the greatest care givers since women generally bear disproportionate burdens of informal care in Nigeria. Older Nigerians' expectation that government should be responsible for their welfare in old age is in tandem with global best practices where governments provide social 
protection programmes and services to address old age challenges such as social security, MEDICARE and old age income.

Table 4: Sex of respondents and awareness of social welfare services for elderly in Lagos State

\begin{tabular}{|l|l|l|l|l|}
\hline Sex & Aware of services & Not aware of services & No response & Total \\
\hline Male & $33(3.9 \%)$ & $791(93.3 \%)$ & $24(2.8 \%)$ & $848(100 \%)$ \\
\hline Female & $17(3.6 \%)$ & $443(93.7 \%)$ & $13(2.7 \%)$ & $473(100 \%)$ \\
\hline Total & $50(3.8 \%)$ & $1234(93.4 \%)$ & $37(2.8 \%)$ & $1321(100 \%)$ \\
\hline
\end{tabular}

$\mathrm{X}^{2}-0.83, \mathrm{df}=2, \mathrm{P}>0.05$ Not statistically significant

When respondents were asked if they knew or were aware of any age-specific formal care services in Lagos State, 93.4 per cent said they were not aware of any social service for older people which underscores the need for home and community-based services in Lagos State to meet the needs of increasing numbers of older people who are without adequate social support in the State. Similar results were also found in terms of older people's awareness of services provided by either private or public institutions to address old age challenges. Subsequently, majority $(95.8 \%)$ had never used any social facilities or benefitted from any social welfare services targeted at assisting elderly residents in Lagos State. In terms of likelihood of living in old people's homes (institutional facilities), an overwhelming majority (80.3\%) were opposed to the idea which confirms cultural norms and older people's preferences for community-based care rather than institutional care.

Some of the reasons cited for preference for home and community-based care in old age include personal comfort, familiarity with their environments, desire to 'age in place' and consolidate on interpersonal relationships in their communities. This is further buttressed by the fact that most respondents (94\%) had robust and good relationships with people in their communities. But, their greatest challenges in old age included financial constraints $(56.3 \%)$, lack of child support (2.4\%), difficulty in discharging domestic responsibilities $(13.2 \%)$, health problems/lack of medication $(15.4 \%)$ and challenges with maintaining family unity $(12.7 \%)$. When the elderly were asked to recommend strategies and programmes they believed could improve their socio-economic well-being in old age, majority $(52.5 \%)$ recommended the introduction of social security and personal welfare services (27.2\%). Other suggestions include opportunity to engage in productive roles/economic roles $(6.7 \%)$ and the provision of senior care centers (day care centers) to reduce boredom while remaining in their communities $(6.8 \%)$. These findings clearly confirm the relevance of home and community-based services in addressing old age care challenges in Lagos State. The benefits of home and community-based services are discussed shortly. 


\section{Benefits of Home and Community-based Services (HCBS)}

Home and community-based care can indeed bring about the 'golden' ages of ageing with destitution and elder neglect becoming rare occurrences in Nigeria. Home and community-based care will also ensure minimal disruption of the lives of older people in Nigeria. With the role transition associated with social change, informal care through family and neighbourhood networks can indeed be revitalized and re-organized to ensure adequate care and support for older people over a long period of time. Home and Community-based care can also assist in bridging the gaps between failure of formal social protection and frailty of informal social support. These gaps can be addressed through strengthening informal care systems like in-home services and communitybased services such as senior day centers and congregate facilities.

\section{Conclusion}

The study findings establish the fact that informal care (home and communitybased services) is critical to socio-economic well-being of older people in Nigeria. From the assessment of older people in Lagos State, informal care is relevant in meeting the basic needs of elders in their homes and communities. Hence, there is strong preference for home and community-based care, generally adjudged to be 'sensitive' to elders' peculiar needs and critical to promoting dignity and independence in old age. Older men and women were also clear in their minds about the nature and quality of care and support that they will require in old age which should inform policy directions in addressing ageing issues and challenges in Nigeria.

\section{Pertinent Questions in addressing Old Age Challenges in Lagos State,} Nigeria

The article proposes that these pertinent questions should be addressed in order to tackle old age challenges in Nigeria:

- How can home and community-based services be developed in a way that will reflect the unique social, economic, cultural and political peculiarities of Nigerian culture and people?

- Can home and community-based care model provide the quality and quantum of care required by older people in Nigeria bearing in mind the diversity of its populations in both rural and urban areas?

- What roles will the three tiers of Government (Federal, State and Local Government areas) play in developing sustainable old age care services that can be delivered at homes or communities?

- How will the different tiers of government in Nigeria share the huge responsibilities associated with providing old age services that can integrate informal care with the traditional obligatory roles of families to cater for its older members (filial piety)? 
- How can the Western styled community-based models (e.g. in the United States) be applicable to Nigerian contexts without compromising Nigerian cultural nuances and norms?

\section{Policy Directions}

- There is need to identify and strengthen the domains of current needs of older people in their homes and communities especially in carrying out activities of daily living (ADLs) and instrumental activities of daily living (IADLs).

- Senior care centers and recreational facilities should be located in each local government area or within walking distance to the homes of Nigerian elderly. Alternatively, the governments, public-spirited individuals and organizations should provide subsided public transportation services which will assist the elderly in gaining access to their preferred facilities (senior day center) in their communities. The senior care centers should also focus on health and wellness programmes that are sensitive to elders' needs in Nigeria.

- Federal and State governments should develop robust geriatric frameworks and designs that will help older people to have access to social welfare services such as old age income, health services and recreational facilities as a matter of priority.

- Adequate assistance should also be given to older people who have difficulty in performing ADLs and IADLs in their homes. The Nigerian Governments should also provide incentives (monetary and non-monetized benefits) to care givers, usually family members to reduce the burdens of care giving.

- The Nigerian Governments should institute regulatory agencies which will develop and enforce structured guidelines (template) on social service planning and case management. This will ensure that elder care is effectively monitored and evaluated by relevant regulatory agencies and bodies aimed at ensuring adequate geriatric care management which will reduce elder abuse.

- Shrinking social support networks (informal care), loss of income, poor social protection (lack of social security) and changes in living arrangements have negative effects on the quantum and quality of old age care in Nigeria. Nigerian Government and charitable organizations should introduce specific welfare programmes (old age income, health care, social welfare services) to address these gaps aimed at promoting well-being of older people.

- Corporate organizations and governments (stakeholders) should fund ageing research and evidence-based advocacy which will inform policies and programmes aimed at identifying the peculiar needs and challenges of Nigerian elderly. This will greatly assist in developing strategies and progrmames that will improve the living conditions of older people in Nigeria. 


\section{References}

Aboderin, I. 2005. Research on Ageing in Africa: the need to forge directions. Generations Review. 15(3).

Ajala, K. 2006. The changing perception of ageing in Yoruba culture and its implications on the health of the elderly. Anthropologist. 8(3): 181-188.

Akeredolu-Ale, E.O. and Aribiah, O. 2001. Public Policy and Old-Age Security in Nigeria. Ibadan: Center for Social Policy.

Amaike, B. \& Bammeke, F. 2013 Gender, Older persons and Expectations for Care in Lagos State, Nigeria. A paper presented at the Nigerian Association of Social Work Educators (NASWE): University of Benin, Benin City, Edo State, Nigeria.

Amaike, B. 2011. Quality of Life of Destitute Older people in Metropolitan Lagos. UNILAG Sociological Review. 9: 1-37.

Amaike, G.O. 2009. Livelihood and Living Conditions of Formal Sector Retirees in Lagos State, Nigeria. Unpublished Ph.D. Thesis. Lagos: Department of Sociology and School of Postgraduate Studies, University of Lagos, Lagos State, Nigeria.

Apt, N.A. 2002. Preface. Ageing in Africa. Makoni, S. \& Stroeken, K. (eds.). Ashgate, Aldershot. ix-xi.

Atchley, R.C. 1985. Social forces and Ageing: an Introduction to social gerontology. $4^{\text {th }}$ ed. Belmont, California: Wadsworth.

Bengtson, V.L. et al. 1997 Theory, Explanation and a third generation of theoretical development in social gerontology. Journal of Gerontology: Social Sciences. 52B(2): S72-S88.

Bohman, D.M.; Van-Wyk, N.C. \& Ekman, S. 2011. South Africans Experiences of being Old \& of Care \& Caring in a Transitional Period. International Journal of Older People Nursing. 6: 187-195.

Bronstein, et al. 2011. A neighbourhood naturally occurring retirement community: views from providers \& residents. Journal of Applied Gerontology. 30(1): 104-112.

Burgess, E. 1960. Personal and Social Adjustment in old age. The Aged and Society. In M. Derber (ed.). Champaign III industrial Research Associations.

Chapman, S.A.; Keating, N. \& Eales, J. 2003. Client-centered, Communitybased Care for frail Seniors. Health \& Social Care in the Community. 11(3): 253-261.

Cowgill, D.O. 1974. Ageing and Modernization: A revision of the theory in Later Life, Communities and Environmental policy. In Gubrium, J.F. (ed.). Springfield: Thomas. III: 123-46.

Cowgill, D.O. and Holmes, L.D. 1972. Ageing and Modernization. New York: Appleton-Century-Crofts.

Donlan, W.T. 2011. The Meaning of Community based Care for frail Mexican American Elders. International Social Work. Sage. 54(3): 388-403. 
Dooley, W.K.; Shaffer, D.R.; Lance, C.E. \& Williamson, G.M. 2007. Informal Care Can be Better Than Adequate: Development \& Evaluation of the Exemplary Care Scale. Rehabilitation Psychology.

Egwu. 2013. Modernization \& Ageing patterns in Nigeria. International Journal of Social Sciences and Humanities Reviews. 4(1): 116-119.

Ejechi. 2013. A Comparative study of physical activity \& cognitive function of a sample of elderly Nigerians living in a rural and an urban area. International Journal of Humanities \& Social Science. 3(6): 140-150.

Healy, J. 2002. The Care of Older People: Australia and the United Kingdom. Social Policy \& Administration. 36(1): 1-19.

Heslop, A. 1999. Poverty and Livelihood in an Ageing World in Help Age International. The Ageing and Development Report. London: Earthscan.

Gantert, T.M.; McWilliam, C.L.; Ward-Griffin, C.; Allen, N.J. 2008. The Key to Me: Seniors' Perception of Relationship-Building with In-Home Service Providers. Canadian Journal on Ageing. Cambridge: University Press. 27(1): 23-34.

Jullamate, P. 2008. The Study of Informal Rehabilitation Performed by Thai caregivers of Elderly Stroke Patients. Unpublished Ph.D. dissertation, University of Porto, Porto, Portugal.

Lehning, A.; Kim, M.H. \& Dunkle, R.E. 2013. Facilitators of Home \& Community-based Services Use by Urban African American Elders. Journal of Ageing \& Health. 25(3): 439-458.

Lemon, B.W.; Bengtson, V.L. and Peterson, J.A. 1972. An exploration of the Activity Theory of Ageing: Activity types and life satisfaction among inmovers to a Retirement Community. Journal of Gerontology. 27: 511-523.

Matcha, D.A. 1997. The Sociology of Ageing-A Social Problems Perspective. Boston: Allyn and Bacon.

McCann, S. \& Evans, D. 2002. Informal Care: The views of People Receiving Care. Health and Social Care in the Community. 10: 221-228.

Moody, H.R. 2012. Ageing: Concepts and Controversies. $6^{\text {th }}$ edition. Sage Publication. United States: Pine Forge Press.

Moody, H.R. 2002. Ageing: Concepts and Controversies. $4^{\text {th }}$ edition. Sage Publication. United States: Pine Forge Press.

Novak, M. 2012. Issues in Ageing. Boston: Pearson $3^{\text {rd }}$ Edition.

Oppong, C. 2006. Familial roles and Social Transformations of Older Men and Women in Sub-Saharan Africa. Research on Ageing. 28: 654-668.

Rosenberg, E.; Jullamate, P. \& Azeredo, Z. 2009. Informal Care giving: Crosscultural Applicability of the Person-Environment Model. Health Sociology Review. 18(4).

Suhonen, R.; Charalambos, A.; Scolt, M.; Katajisto, J. \& Puro, M. 2012. Caregivers Work Satisfaction and Individualized Care in Care Setting for Older People. Journal of Clinical Nursing. 22: 479-490.

Swan, J. et al. 2008. Getting tougher for the fourth quarter: Boomers and Physical Activity. Journal of Ageing \& Physical Activity. 16(3): 261-279. 
Szinovacz, M. 1996. 'Couples' Employment/Retirement Patterns and Perceptions of Marital Quality. Research on Ageing. 18: 243-268.

Togonu-Bickersteth, F. 1997. Gender Difference in Expressed Satisfaction with Care from Adult Children among Older Rural Yoruba' Southern African Journal of Gerontology. 6(1): 3-6.

United Nations Populations Division (UNPD). 2009. World Population Prospects: The 2006 Revision. UNDP, New York. Available at www.esa.un.org retrieved on 6 August, 2013.

UNFPA and Help Age International. 2012. Ageing in the Twenty-First Century: A Celebration and A challenge. New York and London: UNFPA \& HAI.

Wister et al. 2010. Longlife Educational Practices and Resources in Enabling Health Literacy among Older Adults. Journal of Ageing and Health. 22(6): 827-854.

Wolff, J.L. and Agree, E.M. 2004. Depression among Recipients of Formal Care: The Effects of Reciprocity, Respect \& Adequacy of Support. Journal of Gerontology. 59: 173-180.

Wu, B.; Carter, M.W.; Goins, R.T. and Cheng, C. 2005. Emerging Services for Community-based Long-Term Care in Urban China: A Systematic Analysis of Shanghai's Community-based agencies. Journal of Ageing and Social Policy. 17(4): 37-60.

$\mathrm{Xu}$, Q. and Chow, J.C. 2011. Explaining the Community-based Service Delivery Model: Elderly Care in China. International Social Work. 54(3): 374-387. Sage. 